\title{
Serum lipoprotein(a) concentrations and apolipoprotein(a) phenotypes in the families of NIDDM patients
}

\author{
K.Hirata ${ }^{1}$, K. Saku ${ }^{1}$, S. Jimi ${ }^{2}$, S. Kikuchi ${ }^{3}$, H.Hamaguchi ${ }^{3}$, K. Arakawa ${ }^{1}$ \\ ${ }^{1}$ Department of Internal Medicine, Fukuoka University School of Medicine, Fukuoka, Japan \\ ${ }^{2}$ Department of Pathology, Fukuoka University School of Medicine, Fukuoka, Japan \\ ${ }^{3}$ Department of Human Genetics, Institute of Basic Medical Sciences, University of Tsukuba, Tsukuba, Japan
}

Summary We studied the quantitative and qualitative characteristics of lipoprotein(a) $[\mathrm{Lp}(\mathrm{a})]$ as a function of apolipoprotein(a) [apo(a)] phenotype in $87 \mathrm{mem}$ bers ( 42 males, 45 females) of 20 diabetic families, 26 of whom were diagnosed with non-insulin-dependent diabetes mellitus (NIDDM) with moderate glycaemic control ( $\left.\mathrm{HbA}_{1 \mathrm{c}} 7.1 \pm 1.2 \%\right)$. Apo(a) phenotyping was performed by a sensitive, high-resolution technique using SDS-agarose/gradient PAGE (3-6\%). To date, 26 different apo(a) phenotypes, including a null type, have been identified. Serum Lp(a) levels of NIDDM patients and non-diabetic members of the same family who had the same apo(a) phenotypes were compared, while case control subjects were chosen from high-Lp(a) non-diabetic and low-Lp(a) nondiabetic groups with the same apo(a) phenotypes in the same family. Serum $L p(a)$ levels were significantly higher in NIDDM patients than in non-diabetic subjects $(39.8 \pm 33.3$ vs $22.3 \pm 19.5 \mathrm{mg} / \mathrm{dl}$, $p<0.05)$. The difference in the mean Lp(a) level between the diabetic and non-diabetic groups was sig- nificantly $(p<0.05)$ greater than that between the high-Lp(a) non-diabetic and low-Lp(a) non-diabetic groups. An analysis of covariance and a least square means comparison indicated that the regression line between serum $L p(a)$ levels $[\log L p(a)]$ and apo(a) phenotypes in the diabetic patient group was significantly $(p<0.01)$ elevated for each apo(a) phenotype, compared to the regression line of the control group. These data, together with our previous findings that serum $L p(a)$ levels are genetically controlled by apo(a) phenotypes, suggest that $L p(a)$ levels in diabetic patients are not regulated by smaller apo(a) isoforms, and that serum $L p(a)$ levels are greater in diabetic patients than in non-diabetic family members, even when they share the same apo(a) phenotypes. [Diabetologia (1995) 38: 1434-1442]

Key words Apolipoprotein(a), diabetes mellitus, family study, lipids, lipoprotein(a), lipoproteins, phenotypes.
Received: 10 November 1994 and in final revised form: 6 June 1995

Corresponding author: Dr. K.Saku, Department of Internal Medicine, Fukuoka University School of Medicine, 45-1-7 Nanakuma Jonanku, Fukuoka 814-01, Japan

Abbreviations: Lp(a), Lipoprotein(a); apo(a), apolipoprotein(a); NIDDM, non-insulin-dependent diabetes mellitus; TC, total cholesterol; LDL, low density lipoprotein; TG, triglycerides; HDL-C, high density lipoprotein-cholesterol; LDL-C, low density lipoprotein-cholesterol; PBS, phosphate buffered saline.

The first two authors contributed equally to this work
Human lipoprotein(a) $[\mathrm{Lp}(\mathrm{a})]$ was first demonstrated by Berg [1] in 1963 as a genetic variant of low density lipoprotein (LDL). Lp(a) is a cholesterol-rich lipoprotein which has a composition similar to that of LDL. Lp(a) contains apo B disulphide-linked to apolipoprotein(a) [apo(a)] which is highly homologous to plasminogen and affects the human coagulation system [2-6]. Plasma concentrations of $L p(a)$ in humans vary between individuals from less than $1 \mathrm{mg} /$ $\mathrm{dl}$ to more than $100 \mathrm{mg} / \mathrm{dl}$ and these concentrations are genetically controlled by apo(a) phenotypes [7$10]$. The heterogeneity of $L p(a)$ density has been attributed to the presence of apo(a) species with different molecular weights, based on the repetition of 
kringle IV [11]. Apo(a) molecular weights are inversely correlated with plasma $L p(a)$ levels [7-13].

Recently, an increased plasma concentration of $\mathrm{Lp}(\mathrm{a})$ has been reported in diabetes mellitus, chronic renal failure, ischaemic heart disease, and other atherosclerotic diseases [13-18]. However, these reports have not always been based on case control studies.

Patients with non-insulin-dependent diabetes mellitus (NIDDM) have a higher morbidity and mortality from ischaemic heart disease [19]. They also show abnormal plasma lipid and lipoprotein levels (atherogenic changes), and have a significantly increased risk of microvascular disease. Several reports have found different $L p(a)$ concentrations in individuals who have the same phenotype of the apo(a) gene, although similar $\mathrm{Lp}(\mathrm{a})$ concentrations are observed within families [20-22]. Many population studies have reported that diabetic patients have higher $\mathrm{Lp}$ (a) concentrations, and we had observed a similar tendency in our previous study [13]. From the present study of families with the same apo(a) phenotypes it should be possible to clarify whether the increased $\mathrm{Lp}$ (a) concentration in diabetic patients is secondary to diabetes.

\section{Subjects and methods}

Family study. We investigated 87 subjects (42 males, 45 females) from 20 Japanese families, 26 of whom were diagnosed with NIDDM (17 males, 9 females). All of the probands were selected at random from our University hospital and two other teaching hospitals. We used families in which the NIDDM patients were non-smokers, and all of the family members lived in Fukuoka Prefecture, Japan. Although 15 of the family members examined did not live with their respective probands, $100 \%$ of the family members were assayed. Only 2 of the 87 subjects studied were smokers. Fasting lipid, lipoprotein, blood glucose and $\mathrm{HbA}_{1 \mathrm{c}}$ values were determined in all subjects. Their average glycaemic control was moderate $\left(\mathrm{HbA}_{1 \mathrm{c}} 7.1 \pm 1.2 \%\right)$. Of these patients, 3 were receiving insulin treatment, 14 were receiving hypoglycaemic agents, and 9 were treated with diet therapy only. The diagnosis of diabetes was based on a 75 -g oral glucose tolerance test (OGTT), the use of oral hypoglyceridaemic agents, or insulin therapy. Although the disease duration was not entirely clear, all of the diabetic patients had been diagnosed for at least 3 years. The exclusion of diabetes was based on both fasting blood glucose less than $6.11 \mathrm{mmol} / 1$ and $\mathrm{HbA}_{1 \mathrm{c}}$ less than $6.0 \%$. When a subject showed either abnormal fasting blood glucose or $\mathrm{HbA}_{1 \mathrm{c}}$, 75-g OGTT was performed to rule out diabetes. The diagnosis of coronary heart disease was based on coronary angiography. The diagnosis of arteriosclerosis obliterans was based on a clinical episode of intermittent claudication and artery angiography. The diagnosis of hypertension was based on blood pressure above $160 / 95 \mathrm{~mm} \mathrm{Hg}$ on more than two occasions, or the use of anti-hypertensive drugs. All of the studies described here were performed with the consent of each proband and the members of his or her family.

Chemical determinations. Blood samples were taken after an overnight fast. Serum total cholesterol (TC) and triglycerides
(TG) were determined by enzymatic methods $[23,24]$. The heparin $\mathrm{CaCl}_{2}$ precipitation method was used to assay serum high-density lipoprotein cholesterol (HDL-C) [25]. Low-density lipoprotein cholesterol (LDL-C) was calculated using the formula of Friedewald et al. [26]. $\mathrm{HDL}_{2}$ and $\mathrm{HDL}_{3}$ subfractions were separated by an ultracentrifugation method [27]. Serum apo AI, apo AII, apo B, apo CII, apo CIII, and apo E levels were determined by the turbidity immuno-assay method [28]. Serum Lp(a) was determined by ELISA using a Tint Eliza Lp(a) kit (Biopool, Umea, Sweden) [29]. Plasma insulin levels were determined by immunoradiometric assay using an INSULIN RIABEAD II kit (Dinabot, Tokyo, Japan) [30]. Inter-assay and intra-assay coefficients of variation for all of the measurements in our laboratory were less than $5.5 \%$.

Plasma lipoprotein isolation. Venous blood was collected in EDTA tubes and then centrifuged at $4^{\circ} \mathrm{C}$. The plasma fraction (approximately $1 \mathrm{ml}$ ) at density $(d)<1.12 \mathrm{~g} / \mathrm{ml}$ was separated by ultracentrifugation (Beckman TL-100 Tabletop Uitracentrifuge, TLA-100.2 fixed-angle rotor, Beckman Instrument, Inc., Palo Alto, Calif., USA), using polycarbonate centrifuge tubes. Tube slicing was performed using a Centrifuge Slicer (Beckman).

Apo(a) phenotyping. Apo(a) phenotyping was performed in all 87 subjects by the method of Kikuchi et al. [12], as described previously [13]. Briefly, 2-5 $\mu$ l of lipoprotein fraction $(d<1.12 \mathrm{~g} / \mathrm{ml})$ was mixed with an equal volume of a sample buffer which contained $0.25 \mathrm{~mol} / 1$ Tris- $\mathrm{HCl}$ (pH 6.8), $20 \%$ sucrose, $10 \%$ SDS, $10 \%$ 2-mercaptoethanol, and $0.02 \%$ Bromophenol Blue. For the stacking gel, $1.2 \%$ agarose gel containing $0.125 \mathrm{~mol} / 1$ Tris- $\mathrm{HCl}(\mathrm{pH} 6.8), 0.2 \% \mathrm{SDS}$, and $0.5 \% 2-$ mercaptoethanol was used instead of polyacrylamide gel. For the running gel, we used 3-6\% gradient polyacrylamide slab gels containing $0.375 \mathrm{~mol} / 1$ Tris- $\mathrm{HCl}(\mathrm{pH} 8.8)$ and $0.2 \%$ SDS. The running buffer contained $25 \mathrm{mmol} / 1$ Tris, $0.19 \mathrm{~mol} / \mathrm{l}$ glycine, and $0.2 \%$ SDS. The control samples contained the lipoprotein fraction from four individuals. Electrophoresis was performed at a constant current of $5 \mathrm{~mA}$ for $3 \mathrm{~h}$ and then at $3 \mathrm{~mA}$ for an additional $18 \mathrm{~h}$ at room temperature. Electrophoretic transfer of protein from gel to nitrocellulose membrane filters (BA83, Schleicher \& Schuell, Dassel, Germany) was performed for $2 \mathrm{~h}$ at a constant current of $180 \mathrm{~mA}$ with a blotting buffer $(7 \times$ running buffer containing $10 \%$ methanol). The filter was blocked with $0.2 \%$ gelatin in phosphate buffered saline (PBS) and incubated in $1 \%$ bovine serum albumin in PBS containing $0.1 \%$ anti-apo(a) monoclonal antibody. The anti-apo(a) monoclonal antibody was prepared using purified human apo(a) and did not cross-react with human plasminogen or other plasma proteins (Nakagawa et al., unpublished data). Peroxidase-conjugated anti-mouse IgG rabbit serum $(0.1 \%$ in PBS) was used as the second antibody, and the patterns were visualized using $0.01 \%$ 3,3'-diaminobenzidine, tetrahydrochloride and $0.1 \% \mathrm{H}_{2} \mathrm{O}_{2}$ in PBS.

\section{Statistical analysis}

All calculations were performed using the Statistical Analysis System (SAS) at the Fukuoka University Computer Center. The data are all presented as the mean \pm SD. Since a Kolmogorow-Smirnov test showed a significant deviation from the normal distribution for $L p(a)$, the Mann-Whitney U-test was used to compare values in the patient groups with those of the control subjects. The pairwise test was used to compare values in the diabetic group with those in the non-diabetic group af- 
Table 1. Serum lipoproteins and apolipoproteins in subjects studied

\begin{tabular}{|c|c|c|}
\hline & \multicolumn{2}{|l|}{ Subjects } \\
\hline & Diabetic $(n=26)$ & Non-diabetic $(n=61)$ \\
\hline Age (years) & $59.9 \pm 9.1^{b}$ & $40.6 \pm 18.2$ \\
\hline $\mathrm{TC}(\mathrm{mmol} / \mathrm{l})$ & $5.92 \pm 1.61^{\mathrm{a}}$ & $4.90 \pm 0.92$ \\
\hline $\mathrm{TG}(\mathrm{mmol} / \mathrm{l})$ & $2.01 \pm 1.71^{b}$ & $1.10 \pm 0.85$ \\
\hline $\mathrm{HDL}-\mathrm{C}(\mathrm{mmol} / \mathrm{l})$ & $1.13 \pm 0.23^{\mathrm{b}}$ & $1.39 \pm 0.38$ \\
\hline $\mathrm{HDL}_{2}-\mathrm{C}(\mathrm{mmol} / \mathrm{l})$ & $0.70 \pm 0.24^{\mathrm{a}}$ & $0.90 \pm 0.35$ \\
\hline $\mathrm{HDL}_{3}-\mathrm{C}(\mathrm{mmol} / \mathrm{l})$ & $0.68 \pm 0.08^{\mathrm{a}}$ & $0.55 \pm 0.09$ \\
\hline $\mathrm{Lp}(\mathrm{a})(\mathrm{mg} / \mathrm{dl})$ & $39.8 \pm 33.3^{b}$ & $22.3 \pm 19.5$ \\
\hline Apo AI $(\mathrm{mg} / \mathrm{dl})$ & $117.9 \pm 20.2^{\mathrm{a}}$ & $132.8 \pm 25.2$ \\
\hline Apo AII (mg/dl) & $30.5 \pm 7.7$ & $31.4 \pm 5.8$ \\
\hline Apo B (mg/dl) & $115.0 \pm 39.9^{b}$ & $88.4 \pm 23.5$ \\
\hline Apo CII (mg/dl) & $5.2 \pm 3.5^{\mathrm{b}}$ & $3.3 \pm 1.5$ \\
\hline Apo CIII (mg/dl) & $13.9 \pm 9.6^{\mathrm{b}}$ & $9.6 \pm 3.7$ \\
\hline Apo E (mg/dl) & $6.4 \pm 4.4^{\mathrm{b}}$ & $4.6 \pm 1.3$ \\
\hline $\mathrm{HbA}_{1 \mathrm{c}}(\%)$ & $7.1 \pm 1.2^{b}$ & $4.7 \pm 0.7$ \\
\hline
\end{tabular}

Data are mean \pm SD.

${ }^{\mathrm{a}} p<0.05 ;{ }^{\mathrm{b}} p<0.01$

ter adjusting for family and apo(a) isoform. We first identified members of the same family with the same apo(a) phenotypes. After matching for family and apo(a) phenotypes, pairing was performed according to presence or absence of diabetes. For a control group, we separated the high- and low- Lp(a) groups from the non-diabetic subjects with the same apo(a) phenotypes. An analysis of covariance was used to compare groups after adjusting for confounding factors (age, sex, TC, TG, diseases, etc.) and apo(a) phenotypes, and least-square means were also compared after $\log$ transformation of Lp(a) and after adjusting for apo(a) phenotypes to gain a better understanding of the relationship between the frequency distribution of apo(a) phenotypes and serum $\mathrm{Lp}$ (a) levels in these groups. $p$ values of less than 0.05 were considered to be statistically significant.

\section{Results}

We evaluated serum $L p(a)$ concentrations and apo(a) phenotypes of both diabetic patients $(n=26)$ and their non-diabetic family members $(n=61)$. Serum $\mathrm{Lp}$ (a) concentrations in these groups were 39.8 $\pm 33.3(1-132)$ and $22.3 \pm 19.5(3-112) \mathrm{mg} / \mathrm{dl}$, respectively. The Mann-Whitney U-test showed that Lp(a) levels were significantly $(p<0.01)$ higher in the diabetic patient group than in the non-diabetic group, the former group being significantly older than the latter group.

Serum TC and TG levels in the diabetic group were $5.92 \pm 1.61$ and $2.01 \pm 1.71 \mathrm{mmol} / 1$, respectively, which were higher $(p<0.05)$ than those in the non-diabetic family members $(4.90 \pm 0.92$ and $1.10 \pm 0.85 \mathrm{mmol} / 1$, respectively) (Table 1$)$. Serum HDL-C $(1.13 \pm 0.23$ and $1.39 \pm 0.38 \mathrm{mmol} / \mathrm{l}$, respectively), $\mathrm{HDL}_{2}-\mathrm{C}$ $(0.70 \pm 0.24$ and $0.90 \pm 0.35 \mathrm{mmol} / \mathrm{l}$, respectively), and apo AI $(117.9 \pm 20.2$ and $132.8 \pm 25.2 \mathrm{mg} / \mathrm{dl}$, respectively) were all significantly lower $(p<0.05)$ in the diabetic group than in non-diabetic subjects. Se- rum apo $\mathrm{B}(115.0 \pm 39.9$ and $88.4 \pm 23.5 \mathrm{mg} / \mathrm{dl}$, respectively), apo CII $(5.2 \pm 3.5$ and $3.3 \pm 1.5 \mathrm{mg} / \mathrm{dl}$, respectively), apo CIII (13.9 \pm 9.6 and $9.6 \pm 3.7 \mathrm{mg} / \mathrm{dl}$, respectively), and apo $\mathrm{E}(6.4 \pm 4.4$ and $4.6 \pm 1.3 \mathrm{mg} / \mathrm{dl}$, respectively) were all significantly $(p<0.05)$ higher in the diabetic group. No significant difference was observed in serum apo AII $(30.5 \pm 7.7$ and $31.4 \pm$ $5.8 \mathrm{mg} / \mathrm{dl}$, respectively) between the two groups (Table 1). Furthermore, we compared serum lipid and lipoprotein levels in the diabetic group to those in the non-diabetic group in 22 patients with the same apo(a) phenotypes in the same family. As control subjects, the non-diabetic higher-Lp(a) group and the non-diabetic lower-Lp(a) group with the same apo(a) phenotypes are also listed in Table 2. In the former pair, serum TC levels $(5.72 \pm 1.05$ and $4.67 \pm 0.68 \mathrm{mmol} / 1$, respectively), apo B levels (110.8 \pm 30.6 and $87.3 \pm 23.3 \mathrm{mg} / \mathrm{dl}$, respectively), apo CII levels $(5.0 \pm 2.2$ and $3.0 \pm 1.7 \mathrm{mg} / \mathrm{dl}$, respectively), apo CIII levels (12.2 \pm 5.4 and $8.2 \pm 2.2 \mathrm{mg} / \mathrm{dl}$, respectively), and apo E levels (5.6 \pm 2.2 and $4.2 \pm 0.8 \mathrm{mg} / \mathrm{dl}$, respectively) were higher in the diabetic group than in the non-diabetic group. In the control pair, no significant differences were observed in lipid and lipoprotein levels, except for that of $L p($ a) (Table 2). Again, diabetic patients as well as non-diabetic subjects with high $\mathrm{Lp}(\mathrm{a})$ were significantly older than those in their respective control groups.

$\mathrm{HbA}_{1 \mathrm{c}}$ in the diabetic group $(7.1 \pm 1.2 \%)$ was significantly $(p<0.01)$ higher than that in the non-diabetic group $(4.7 \pm 0.7 \%$ ) (Table 1$)$. The fasting insulin level in the diabetic group $(14.8 \pm 29.9 \mu \mathrm{U} / \mathrm{ml})$ was higher than that in the non-diabetic group $(7.9 \pm 5.0 \mu \mathrm{U} / \mathrm{ml})$. This difference was not statistically significant, even though the insulin levels in insulin-treated patients $(n=3)$ were omitted from the statistical analysis.

In our investigation, 26 different apo(a) isoforms were identified by immunoblot analysis following 3$6 \%$ SDS-PAGE [12]. An example of apo(a) phenotyping is shown in Figure 1. A marker mixture (M) containing apo(a) polymorphs A10, A12, A14, A16, A18 and A21, was applied to each alternate lane, and phenotyping was performed as described above. In a diabetic patient (Fig. $1 \mathrm{a}$ ) and his non-diabetic son (Fig. 1d) in family KS, the levels of Lp(a) which had an A8 isoform were 72 and $32 \mathrm{mg} / \mathrm{dl}$, respectively. In family MT, the serum $\mathrm{Lp}$ (a) level in a diabetic patient (Fig. 1e) with the A8 isoform was $45 \mathrm{mg} / \mathrm{dl}$, while it was $31 \mathrm{mg} / \mathrm{dl}$ (Fig. $1 \mathrm{~g}$ ) and $33 \mathrm{mg} / \mathrm{dl}$ (Fig. $1 \mathrm{~h}$ ) in non-diabetic family members who exhibited the A8 isoform.

Diabetic patients tended to have higher $\mathrm{Lp}(\mathrm{a}) \mathrm{lev}$ els than non-diabetic family members who had the same apo(a) phenotypes (Fig.2). In our study, eight subjects had a single band (isoform) of apo(a), while the remaining subjects had a double band. In these latter subjects, we used the smaller of the two bands 
Table 2. Serum lipoproteins and apolipoproteins in the diabetic group vs non-diabetic group, and in the non-diabetic higher $\mathrm{L}_{\mathrm{p}}$ (a) group vs the non-diabetic lower-Lp(a) group, in 22 pairs with the same apo(a) phenotype

\begin{tabular}{|c|c|c|c|c|}
\hline & \multicolumn{4}{|l|}{ Subjects } \\
\hline & $\begin{array}{l}\text { Diabetic } \\
(n=22)\end{array}$ & $\begin{array}{l}\text { Non-diabetic } \\
(n=22)\end{array}$ & $\begin{array}{l}\text { Non-diabetic [high } \operatorname{Lp}(\mathrm{a})] \\
(n=22)\end{array}$ & $\begin{array}{l}\text { Non-diabetic [low Lp(a)] } \\
(n=22)\end{array}$ \\
\hline Age (years) & $62.2 \pm 10.1$ & $32.8 \pm 13.2^{\mathrm{b}}$ & $43.9 \pm 20.7$ & $30.1 \pm 17.8^{\mathrm{a}}$ \\
\hline $\mathrm{TC}(\mathrm{mmol} / \mathrm{l})$ & $5.72 \pm 1.05$ & $4.67 \pm 0.68^{b}$ & $4.88 \pm 0.90$ & $4.68 \pm 0.84$ \\
\hline $\mathrm{TG}(\mathrm{mmol} / \mathrm{l})$ & $1.85 \pm 1.30$ & $1.16 \pm 1.07$ & $0.97 \pm 0.58$ & $0.90 \pm 0.66$ \\
\hline $\mathrm{HDL}-\mathrm{C}(\mathrm{mmol} / \mathrm{l})$ & $1.17 \pm 0.25$ & $1.31 \pm 0.36$ & $1.38 \pm 0.32$ & $1.37 \pm 0.34$ \\
\hline $\mathrm{HDL} 2-\mathrm{C}(\mathrm{mmol} / \mathrm{l})$ & $0.71 \pm 0.22$ & $0.86 \pm 0.37$ & $0.97 \pm 0.32$ & $0.87 \pm 0.33$ \\
\hline $\mathrm{HDL} 3-\mathrm{C}(\mathrm{mmol} / \mathrm{l})$ & $0.52 \pm 0.06$ & $0.56 \pm 0.08$ & $0.50 \pm 0.05$ & $0.53 \pm 0.11$ \\
\hline $\mathrm{Lp}(\mathrm{a})(\mathrm{mg} / \mathrm{dl})$ & $48.0 \pm 34.5$ & $29.8 \pm 25.4^{\mathrm{b}}$ & $22.4 \pm 12.3$ & $16.7 \pm 10.4^{b}$ \\
\hline Apo AI (mg/dl) & $122.4 \pm 18.4$ & $127.0 \pm 25.3$ & $133.4 \pm 29.0$ & $123.4 \pm 16.8$ \\
\hline Apo AII (mg/dl) & $31.8 \pm 4.8$ & $31.2 \pm 4.1$ & $29.0 \pm 6.1$ & $27.4 \pm 5.7$ \\
\hline Apo B (mg/dl) & $110.8 \pm 30.6$ & $87.3 \pm 23.3^{b}$ & $88.1 \pm 22.3$ & $83.2 \pm 23.0$ \\
\hline Apo CII (mg/dI) & $5.0 \pm 2.2$ & $3.0 \pm 1.7^{\mathrm{b}}$ & $3.2 \pm 1.3$ & $2.8 \pm 1.1$ \\
\hline Apo CIII (mg/dl) & $12.2 \pm 5.4$ & $8.2 \pm 2.2^{\mathrm{a}}$ & $9.4 \pm 3.4$ & $8.5 \pm 2.8$ \\
\hline Apo $E(\mathrm{mg} / \mathrm{dl})$ & $5.6 \pm 2.2$ & $4.2 \pm 0.8^{\mathrm{a}}$ & $4.6 \pm 0.9$ & $4.3 \pm 0.7$ \\
\hline $\mathrm{HbA}_{1 \mathrm{c}}(\%)$ & $6.7 \pm 1.1$ & $4.8 \pm 0.7^{\mathrm{b}}$ & $5.1 \pm 0.5$ & $5.0 \pm 0.7$ \\
\hline
\end{tabular}

Data are mean $\pm \mathrm{SD}$

${ }^{\mathrm{a}} p<0.05 ;{ }^{\mathrm{b}} p<0.01$

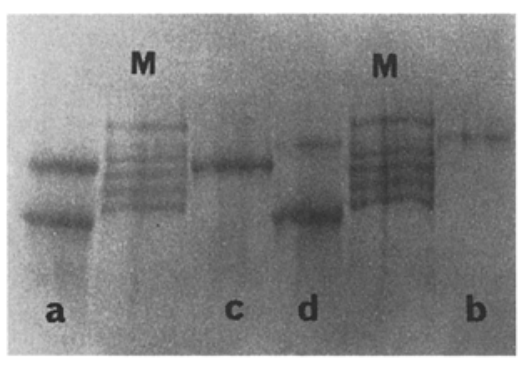

Family KS

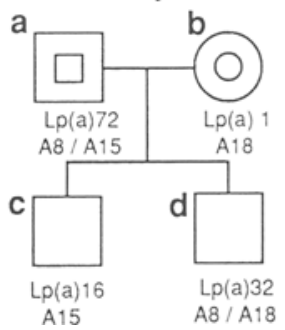

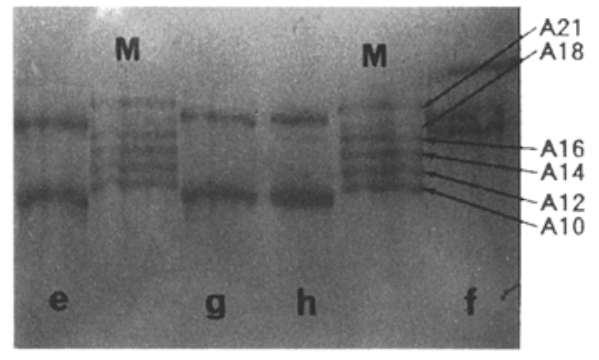

Family MT

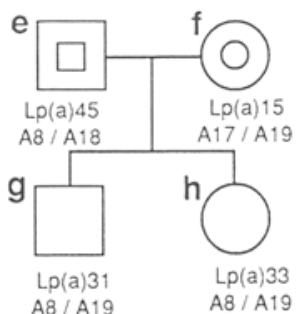

Fig. 1. Apo(a) phenotyping (family KS and family MT) using 3-6\% SDS-agarose/gradient PAGE followed by an immunoblot analysis. A marker (M) mixture contained apo(a) isoforms A10, A12, A14, A16, A18 and A21 for the analysis, since the smaller band has been shown to be well-correlated with $\mathrm{Lp}$ (a) levels in double-banded phenotypes [12]. We compared the serum $L p(a)$ levels in the diabetic and non-diabetic groups (Fig. $3 \mathrm{a}$ ), and in the non-diabetic higher$\mathrm{Lp}$ (a) group and the non-diabetic lower-Lp(a) group (Fig. 3 b) for members of the same family. The daughter in family 3 (Fig. 2), who showed the A16 and A20 isoforms, received the former isoform from her mother and the latter from her father. Therefore, a match could be made between the mother as a nondiabetic higher-Lp(a) (Lp(a): $25 \mathrm{mg} / \mathrm{dl}$ ) and the daughter as a non-diabetic lower-Lp(a) (Lp(a): $14 \mathrm{mg} / \mathrm{dl}$ ). In this case, although her father expressed the A16 isoform, she did not inherit this in her Lp(a) gene. Serum $L p(a)$ levels were significantly higher in the diabetic group than in non-diabetic subjects
( $p<0.0001)$, using the pairwise test. Significant differences $(p<0.0002)$ were also observed between the higher-Lp(a) and lower-Lp(a) groups by the same statistical analysis. The difference between the non-diabetic higher-Lp(a) and lower-Lp(a) groups was compared with the difference between the diabetic and non-diabetic groups. The difference between the latter groups was significantly $(p<0.001)$ greater than that between the former groups according to the $t$-test (Table 2 and Fig. 3).

The regression lines based on $\log \mathrm{Lp}(\mathrm{a})$ and apo(a) phenotypes among these four groups are presented in Figure 4 . The lines were not adjusted for other variables, but we used an analysis of covariance, and least-square means were compared after adjusting for apo(a) phenotypes. The line of the diabetic group was significantly $(p<0.01)$ higher than those of the 

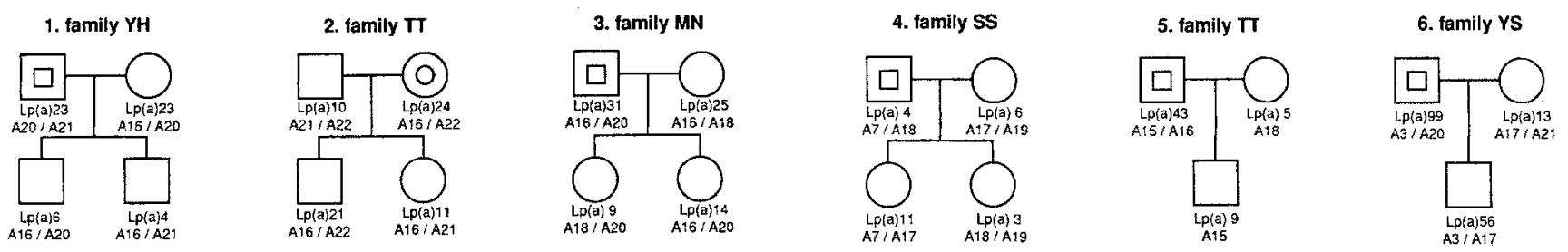
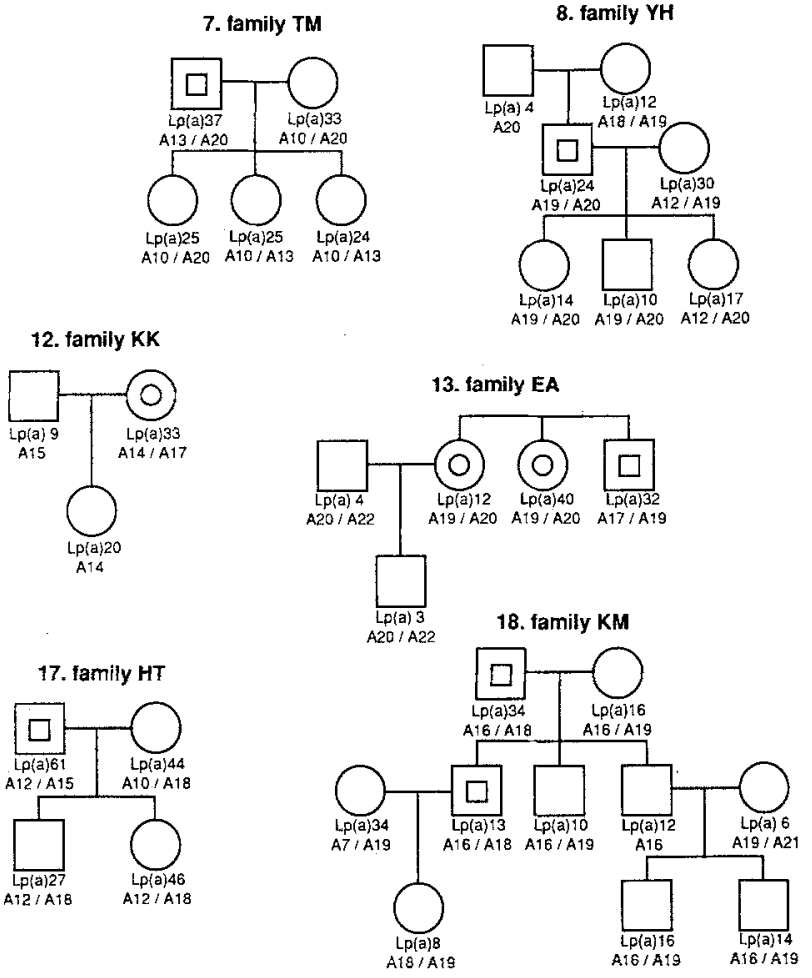

Fig.2. Pedigrees of 20 families with NIDDM (回, (อ): denote diabetic patients)

other three groups. This significant difference was also observed after adjusting for age, gender, and serum TC and TG levels.

Most of the diabetic patients had $L p(a)$ levels higher than those in non-diabetic subjects. The percent changes in $\mathrm{Lp}(\mathrm{a})$ in diabetic subjects vs non-diabetic family members, and apo(a) phenotypes are shown in Figure 5. No significant correlation was found between them.

\section{Discussion}

In the present cross-sectional study, we found that serum $\mathrm{Lp}(\mathrm{a})$ levels were elevated in NIDDM patients, compared to those in non-diabetic subjects after adjusting for the apo(a) phenotypes in the same family. Accelerated atherosclerosis and cardiovascular disease are frequently observed in diabetic patients. Similarly, some of our diabetic patients had other atherosclerotic conditions, such as coronary heart dis-
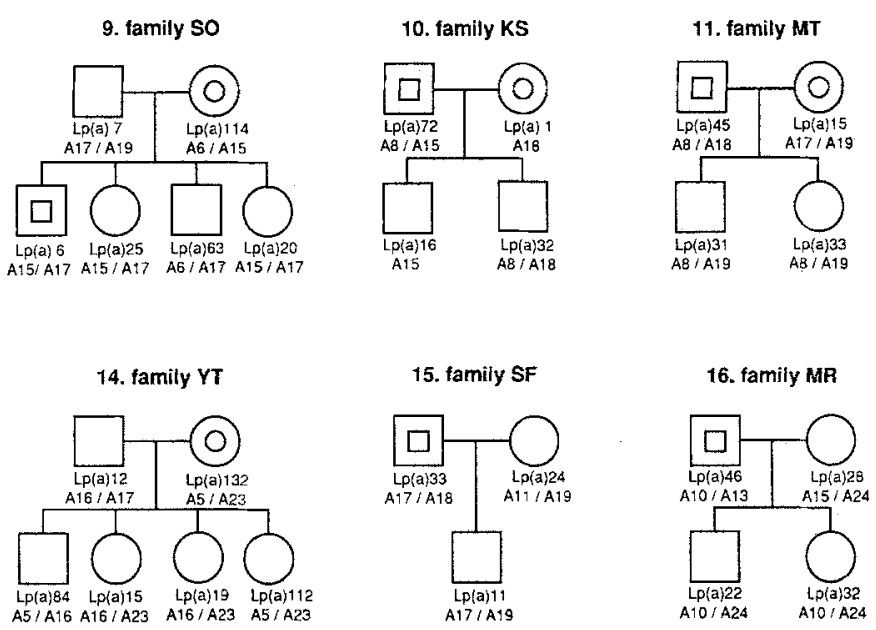

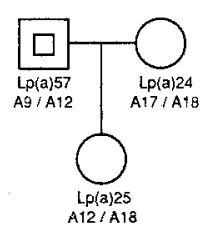

19. family TY
20. family FF

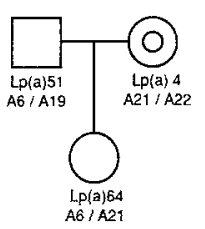

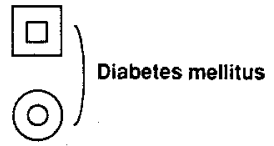

ease $(n=3)$ and arteriosclerosis obliterans $(n=3)$. Some also had chronic disorders, such as chronic renal failure $(n=2)$, and hypertension $(n=11)$, which are often associated with diabetes and atherosclerosis. Increased levels of atherogenic serum lipids, lipoproteins, and apolipoproteins were also found in the patients (Table 1), and there have been reports that $\mathrm{Lp}$ (a) may be an independent risk factor for coronary atherosclerosis $[14,15,17]$.

Many researchers have reported high plasma $\mathrm{Lp}$ (a) levels in diabetic patients, although Haffner et al. [31] conducted a case-control study which gave conflicting results. Urinary albumin loss has been associated with elevated plasma Lp(a) levels [32-34], while at least one study reported no significant elevation in $\mathrm{Lp}(\mathrm{a})$ concentration in patients with diabetic nephropathy [35]. Among the 26 diabetic patients in our study, 11 had nephropathy (microalbuminuria $>30 \mathrm{mg} / \mathrm{g}$ creatinine), and 2 had retinopathy. Serum $\mathrm{Lp}$ (a) levels in patients with $(n=11)$ and without $(n=15)$ nephropathy were $42.5 \pm 29.5 \mathrm{mg} / \mathrm{dl}$ and $62.2 \pm 42.8 \mathrm{mg} / \mathrm{dl}$, respectively. This difference was not significant. Dubrey et al. [36] reported that albumin secretion does not affect serum apo(a) levels in IDDM. We previously reported a similar finding in NIDDM [13]. Heesen et al. [37] and Maioli et al. 

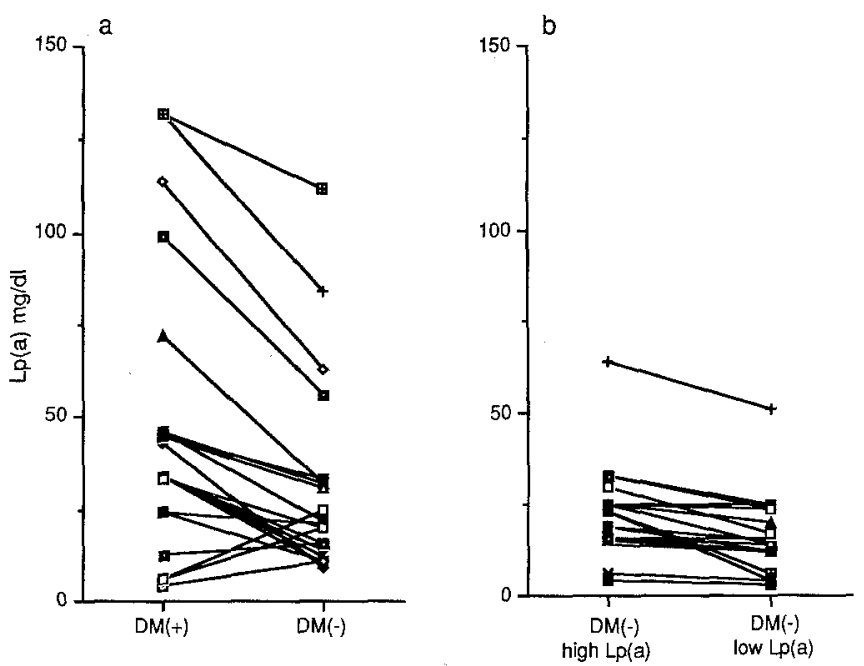

Fig. 3a,b. Comparison of serum $\mathrm{Lp}(\mathrm{a})$ between a) diabetic group and non-diabetic group b) non-diabetic higher-Lp(a) group and non-diabetic lower-Lp(a) group, in family members who have the same apo(a) phenotypes

[38] have reported increased $\mathrm{Lp}(\mathrm{a})$ levels in active diabetic retinopathy and coronary heart disease. However, a similar statistical evaluation could not be performed in our study, since our study group included only one patient with active retinopathy. Up to now we have no definite evidence that the progression of microangiopathy affects the $L p(a)$ concentration. Glycaemic control affects the Lp(a) level in insulindependent-diabetes [39], but apparently does not affect $L p(a)$ levels in NIDDM [31]. We previously reported that glycaemic control and microalbuminuria did not affect the $\mathrm{Lp}(\mathrm{a})$ concentration in NIDDM, while chronic renal failure may be associated with an increase in this concentration [13].

NIDDM patients usually exhibit other disorders, as mentioned above. We tried to subclassify our pati-

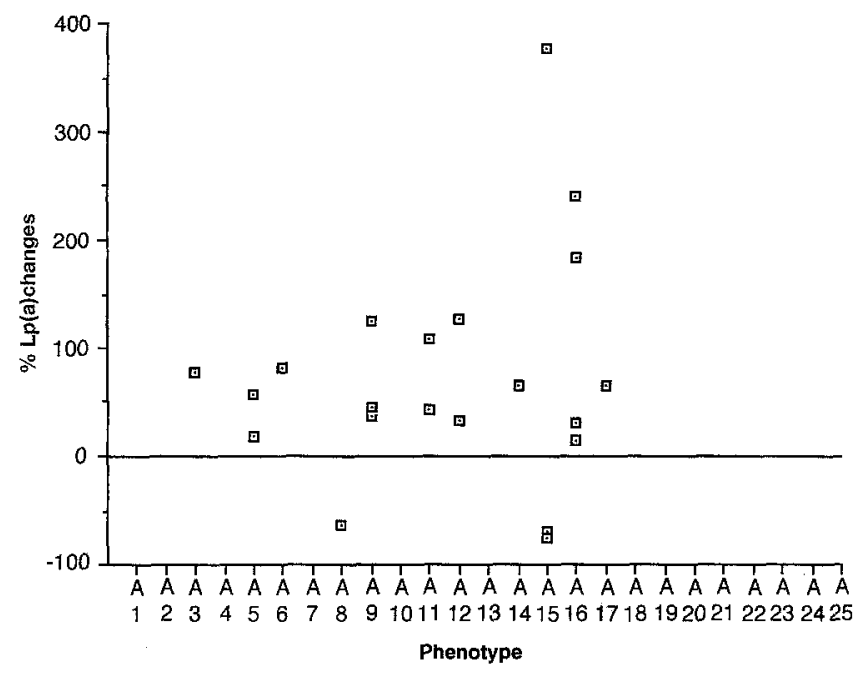

Fig.5. Correlation between the mean changes in $L p(a)$ in diabetic subjects vs non-diabetic family members, and apo(a) phenotypes $\left(y=4.4673 \mathrm{x}+12.16, R^{2}=0.035\right)$

ents and control subjects into several categories, and factors which may affect $\mathrm{Lp}(\mathrm{a})$ levels were computed. An analysis of covariance was performed after adjusting for the presence of diabetes, hypertension, coronary heart disease, chronic renal failure and arteriosclerosis obliterans by the SAS computer program system, i.e., the $R^{2}$ value was calculated by excluding each disease when considering Lp(a) levels (Table 3). We found that diabetes had the greatest effect on elevated serum $L p(a)$ levels; that is, when diabetes was excluded from the analysis, there was no significant contribution to the elevation of serum $\mathrm{Lp}$ (a) levels. However, due to the low number of patients with other diseases, were are not able to draw any definite conclusions about the relation between such diseases and $\mathrm{Lp}(\mathrm{a})$ levels in NIDDM

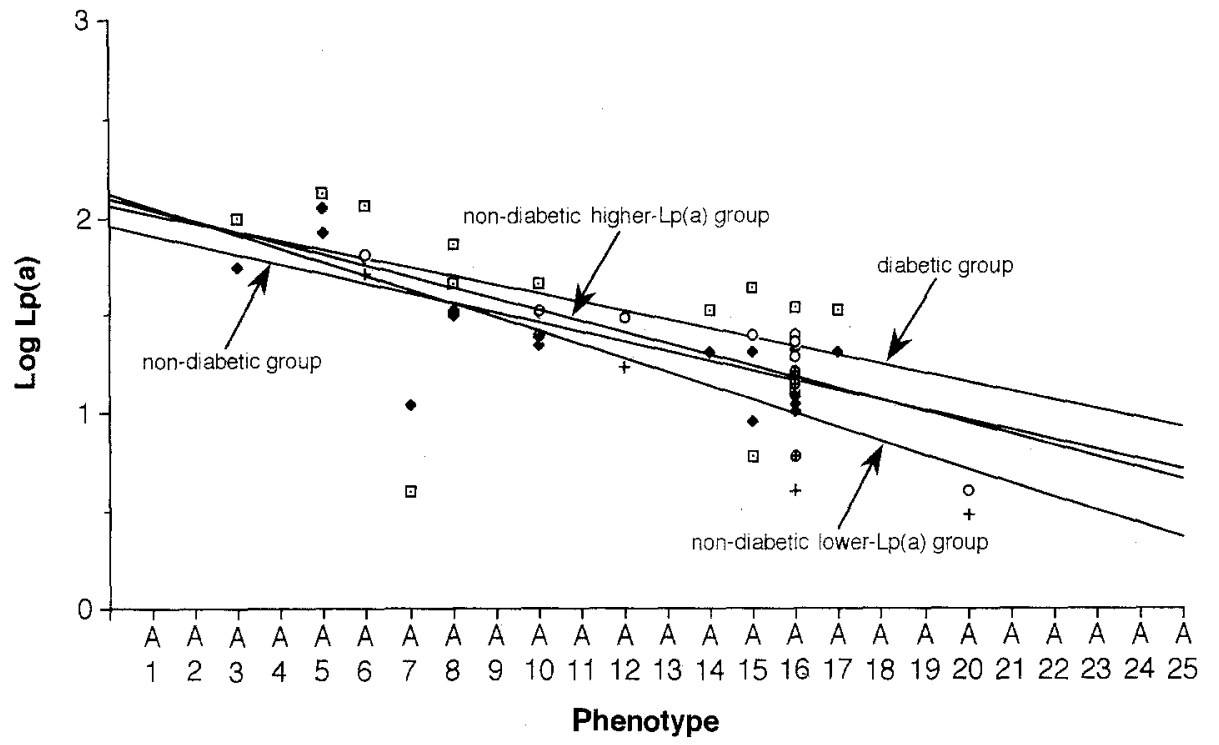

Fig. 4. The regression line of the correlation of serum $\mathrm{Lp}(\mathrm{a})$ concentrations and apo(a) polymorphism in, diabetic group $(y=-4.5288 \mathrm{e}-2 \mathrm{x}+2.0589$, $\left.R^{2}=0.265\right)$, non-diabetic group $(y=$ $\left.-4.9789 \mathrm{e}-2 \mathrm{x}+1.9556, R^{2}=0.602\right)$, non-diabetic higher-Lp(a) group $(y=-5.7298 \mathrm{e}-2 \mathrm{x}+1.7254$, $\left.R^{2}=0.624\right)$, and non-diabetic lower$\mathrm{Lp}$ (a) group $(y=-7.0213 \mathrm{e}-2 \mathrm{x}$ $+1.6915, R^{2}=0.656$ ), in family members who have the same apo(a) phenotype

$\square$, Diabetic group; $\bullet$, non-diabetic group; $O$, non-diabetic higher-Lp(a) group; + , non-diabetic lower-Lp(a) group 
Table 3. The contributing factor index for elevated $\mathrm{Lp}(\mathrm{a})$ levels

\begin{tabular}{lll}
\hline & $R^{2}$ & $p$-value \\
\hline Disease (all) & 0.138 & 0.044 \\
Without DM & 0.101 & 0.084 \\
Without HT & 0.137 & 0.022 \\
Without CHD & 0.136 & 0.023 \\
Without CRF & 0.138 & 0.022 \\
Without ASO & 0.125 & 0.036 \\
\hline
\end{tabular}

Index adjusted for diabetes (DM), hypertension (HT), coronary heart disease (CHD), chronic renal failure (CRF) and arteriosclerosis obliterans (ASO)

from this finding. Considering all of these findings, although diabetic patients have higher plasma $\mathrm{Lp}(\mathrm{a})$ levels, it is difficult to compare plasma $L p(a)$ levels before and after the onset of diabetes in a particular patient.

It has been reported that the apo(a) gene may account for more than $90 \%$ of the inter-individual differences within a pedigree [9]. The plasma $L p(a)$ concentration is regulated by the apo(a) gene, and has a wide range: from less than $1 \mathrm{mg} / \mathrm{dl}$ to more than $100 \mathrm{mg} / \mathrm{dl}$. We have previously reported [13] that the $\mathrm{Lp}$ (a) concentration was negatively correlated with the apo(a) molecular weight. Dubrey et al. [36] studied the effect of IDDM on serum lipid and lipoprotein levels in identical twins and found that IDDM per se has no influence on serum Lp(a) levels, although the correlation within each twin pair was significant. Subjects with the same apo(a) phenotypes within a family show similar plasma Lp(a) levels [20-22]. A similar tendency was observed in our study concerning non-diabetic family members (Fig. 2 and Table 2). Two daughters with A10/A13 in family 7 (Fig. 2) were identical twins, and showed almost identical serum TC (4.29 and $4.29 \mathrm{mmol} / \mathrm{l})$, TG $(0.54$ and $0.54 \mathrm{mmol} / \mathrm{l})$ and $\mathrm{Lp}(\mathrm{a})(25$ and $24 \mathrm{mg} / \mathrm{dl})$ levels. Boomsma et al. [40] reported that factors, other than apo(a) phenotypes may also play a role in determining apo(a) levels.

Utermann et al. [41] reported that genetic transmission of $L p(a)$ protein species can be explained in terms of a series of autosomal codominant alleles. Our data indicate that the apo(a) gene was co-segregated in all 20 families. When two different apo(a) phenotypes exist in a particular individual, the smaller apo(a) isoform has a greater influence on the $\mathrm{Lp}$ (a) concentration [12]. Therefore, we used the smaller apo(a) isoform in our analysis of the relationship between serum $\mathrm{Lp}(\mathrm{a})$ levels and apo(a) isoforms. In our study, the diabetic patients were generally older than the non-diabetic subjects. However, Jenner et al. [42] reported that plasma levels of $L p(a)$ were not affected by age or sex. Serum $L p(a)$ levels in diabetic patients were significantly higher than those in nondiabetic subjects after adjusting for apo(a) phenotypes, apart from family 1 and family 5 (Fig.2). We first identified members of the same family with the same smaller apo(a) phenotypes. After matching for family and apo(a) phenotypes, pairing was performed taking into account presence or absence of diabetes. For a control group, we separated the highand low-Lp(a) groups (Table 2 and Fig. 3). The difference between the non-diabetic higher-Lp(a) and nondiabetic lower-L $p(a)$ groups was compared with that between the diabetic and non-diabetic groups. The latter difference was significantly greater than the former difference, using the $t$-test, which indicates that diabetes is strongly associated with increased $\mathrm{Lp}(\mathrm{a})$ levels. The percent increase in $\mathrm{Lp}(\mathrm{a})$ in diabetic subjects versus that in non-diabetic family members showed no correlation with the molecular weight of apo(a) (Fig.5, $p=0.42$ ). In the control group, no significant difference was observed in lipid and lipoprotein levels, except for that of $L p(a)$. These findings indicate that diabetes may increase Lp(a) levels through some mechanism other than the apo(a) gene.

Among family members with the same apo(a) phenotype, patients with $\mathrm{Lp}$ (a) levels lower $(1-6 \mathrm{mg} / \mathrm{dl})$ than those of non-diabetics [families 4, 9 (male patients), and 10 (female patient)] had high TG levels (4.40, 5.44 and $7.45 \mathrm{mmol} / 1$, respectively). Serum TG levels are expected to be higher in diabetic patients than in normal control subjects. However, plasma TG levels of other diabetic patients in our study were less than $3.4 \mathrm{mmol} / 1$. High TG levels may affect serum Lp(a) measurement, although Cohn et al. [43] found that there was no difference in the total plasma $\mathrm{Lp}$ (a) concentration between the fed and fasting states. We previously transformed the serum $L p(a)$ levels of several hundred control subjects and diseased patients to logarithms, and examined the relationship between $\log \mathrm{Lp}(\mathrm{a})$ and TG. However, a negative, rather than a positive relationship was observed in haemodialysis patients [44]. In the present study, no significant relationship was observed between serum TG and $\log \mathrm{Lp}$ (a) levels in control $\left(y=0.002 \mathrm{x}+2.64, R^{2}=0.024\right.$, NS $)$, while a significant negative correlation was observed between TG and $\log \mathrm{Lp}(\mathrm{a})$ in the diabetic group $(y=$ $\left.-0.005 x+4.357, R^{2}=0.472, p<0.0001\right)$. The increased synthesis of TG-rich lipoprotein seen in diabetic patients does not always lead to increased serum Lp(a) levels. Mean plasma insulin levels were higher in the diabetic group than in the non-diabetic group, although this difference was not statistically significant. In our study, the percent difference in $\mathrm{Lp}$ (a) levels in diabetic patients versus those in nondiabetic subjects with the same apo(a) phenotype did not correlate with the percent difference in insulin between the same two groups, which suggests that insulin resistance or secretions may not always be associated with higher serum Lp(a) levels in diabetic subjects. 
Rader et al. [45] have shown that higher levels of $\mathrm{Lp}(\mathrm{a})$ in the smaller apo(a) isoform depended on the rate of production. In our investigation, higher $\mathrm{Lp}(\mathrm{a})$ levels in diabetic patients were not biased by the apo(a) phenotypes. Lp(a) levels are regulated by the apo(a) gene. However, as shown in Figure 4, serum $L p(a)$ levels were significantly increased even after adjusting for all of the phenotypes. This relation was still significant after adjusting for serum levels of TC and TG. In our study, 26 different apo(a) phenotypes were identified and only 26 diabetic patients were studied. Therefore, we did not categorize patients according to apo(a) phenotypes, as Csaszar et al. [46] have done. Diabetic patients tended to show increased $\mathrm{Lp}(\mathrm{a})$ production, as well as that of other lipoproteins, which was not biased by apo(a) phenotypes. Further genetic studies will be needed to clarify the relation between $\mathrm{Lp}(\mathrm{a})$ levels and larger apo(a) isoforms, using an in vivo human kinetic study.

Elevated plasma levels of $L p(a)$ have been shown to be an independent risk factor for coronary artery disease and other atherogenic diseases [13-17, 35]. Our data indicate that NIDDM patients show increased $\mathrm{Lp}$ (a) levels. The present family study data also show more clearly that the increased $L p(a)$ concentration in diabetic patients is secondary to diabetes. Plasma Lp(a) levels were not determined solely by apo(a) isoforms in diseased states, and it is still unclear why diabetic patients show increased $\mathrm{Lp}(\mathrm{a})$ levels.

\section{References}

1. Berg KI (1963) A new serum type system in man - the Lp system. Acta Pathol Microbiol Immunol Scand 59: 369-382

2. Fless GM, ZumMallen ME, Scanu AM (1985) Isolation of apolipoprotein(a) from lipoprotein(a). J Lipid Res 26: 1224-1229

3. Fless GM, ZumMallen ME, Scanu AM (1986) Physicochemical properties of apolipoprotein(a) and lipoprotein(a-) derived from the dissociation of human plasma lipoprotein(a). J Biol Chem 261: 8712-8718

4. MBewu AD, Durrington PN (1990) Lipoprotein(a): structure, properties and possible involvement in thrombogenesis and atherogenesis. Atherosclerosis 85: 1-14

5. McLean JW, Tomlinson JE, Kuang WJ et al. (1989) cDNA sequence of human apolipoprotein(a) is homologue to plasminogen. Nature 330: 132-137

6. Utermann G (1989) The mysteries of lipoprotein(a). Science 246: 904-910

7. Boerwinkle E, Leffert CC, Lin J, Lackner C, Chiesa G, Hobbs HH (1992) Apolipoprotein(a) gene accounts for greater than $90 \%$ of the variation in plasma lipoprotein(a) concentrations. J Clin Invest 90: 52-60

8. Gaubatz JW, Ghanem KI, Guevara JJ, Nava ML, Patsch W, Morrisett JD (1990) Polymorphic forms of human apolipoprotein[a]: inheritance and relationship of their molecular weights to plasma levels of lipoprotein[a]. J Lipid Res 31: $603-613$
9. Kamboh MI, Ferrell RE, Kottke BA (1991) Expressed hypervariable polymorphism of apolipoprotein(a). Am J Hum Genet 49: 1063-1074

10. Cohen JC, Chiesa G, Hobbs HH (1993) Sequence polymorphisms in the apolipoprotein(a) gene; evidence for dissociation between apolipoprotein(a) size and plasma lipoprotein(a) levels. J Clin Invest 91: 1630-1636

11. Gavish D, Azrolan N, Breslow L (1989) Plasma Lp(a) concentration is inversely correlated with the ratio of kringle IV/kringle $\mathrm{V}$ encoding domains in the apo(a) gene. J Clin Invest 84: 2021-2027

12. Kikuchi S, Nakagawa A, Kobayashi K et al. (1993) High degree of genetic polymorphism in apolipoprotein(a) associated with plasma lipoprotein(a) levels in Japanese and Chinese populations. Hum Genet 92: 537-544

13. Hirata K, Kikuchi S, Saku K et al. (1993) Apolipoprotein(a) phenotypes and serum lipoprotein(a) levels in maintenance hemodialysis patients with/without diabetes mellitus. Kidney Int 44: 1062-1070

14. Dahlen GH, Guyton JR, Arrar M, Farmer JA, Kaut JA, Gotto AM Jr (1986) Association of level of lipoprotein $\mathrm{Lp}(\mathrm{a})$, plasma lipids, and other lipoproteins with coronary artery disease documented by angiography. Circulation 74: 758-768

15. Rhoads GG, Dahlen G, Berg K, Morton NE, Dannenberg AL (1986) Lp(a) lipoprotein as a risk factor for myocardial infarction. J Am Med Assoc 256: 2540-2544

16. Murai A, Miyahara T, Fujimoto N, Matsuda M, Kameyama M (1986) $\mathrm{Lp}$ (a) lipoprotein as a risk factor for coronary heart disease and cerebral infarction. Atherosclerosis 59: 199-204

17. Armstrong VW, Cremer P, Eberle E et al. (1986) The association between serum $\mathrm{Lp}(\mathrm{a})$ concentrations and angiographically assessed coronary atherosclerosis. Atherosclerosis 62: 249-257

18. Sandholzer C, Saha N, Kark JD et al. (1992) Apo(a) isoforms predict risk for coronary heart disease. A study in six populations. Arterioscler Thromb 12: 1214-1226

19. Koistinen MJ (1990) Prevalence of asymptomatic myocardial ischemia in diabetic subjects. BMJ 301: 92-95

20. Utermann G, Duba C, Menzel HJ (1988) Genetics of the quantitative $\mathrm{Lp}(\mathrm{a})$ lipoprotein trait. II. Inheritance of Lp(a) glycoprotein phenotypes. Hum Genet 78: 47-50

21. Lackner C, Boerwinkle E, Leffert CC, Rahmig T, Hobbs $\mathrm{HH}$ (1991) Molecular basis of apolipoprotein(a) isoform size heterogeneity as revealed by pulsed-field gel electrophoresis. J Clin Invest 87: 2153-2161

22. Yanagi H, Nakagawa A, Kikuchi S et al. (1993) Frequent occurrence of familial aggregations of high lipoprotein(a) levels associated with small apolipoprotein(a) isoforms. Hum Genet 92: 545-548

23. Allain CC, Poon LS, Chan CS (1974) Enzymatic determination of total cholesterol. Clin Chem 20: 470-475

24. Eggestein M, Kreuntz FH (1966) Eine neue Bestimmung der Neutralfette in Blutserum und Gewebe, Prinzip, Durchführung und Besprechung der Methode. Klin Wochenschr 44: 262

25. Noma A, Nezu-Nakayama K, Kita M, Okabe H (1978) Simultaneous determination of serum cholesterol in highand low-density lipoproteins with use of heparin $\mathrm{Ca}^{2+}$, and anion-exchange resin. Clin Chem 24: 1504-1508

26. Friedewald WT, Levy RI, Fredrickson DS (1972) Estimation of the concentration of low-density lipoprotein cholesterol in plasma, without use of the preparative ultracentrifuge. Clin Chem 18: 499-502

27. Havel RL, Eder HA, Bragton JH (1955) The distribution and chemical composition of ultracentrifugally sepa- 
rated lipoproteins in human serum. J Clin Invest 34: 1345-1353

28. Ikeda T, Shibuya U, Sugiuchi H, Araki S, Uji Y, Okabe H (1991) Automated immunoturbidimetric analysis of six plasma apolipoproteins: correlation with radial immunodiffusion assays. J Clin Lab Anal 5: 90-95

29. Abe A, Maeda S, Makino K et al. (1988) Enzyme-linked immunosorbent assay of lipoprotein(a) in serum and cord blood. Clin Chim Acta 177: 31-40

30. Mogan CR, Lazarow A (1963) Immunoassay of insulin: two antibody system. Diabetes 12: 115-126

31. Haffner SM, Tuttle KR, Rainwater DL (1992) Lack of change of lipoprotein(a) with improved glycemic control in subjects with type II diabetes. Metabolism 41: 116-120

32. Jenkins AJ, Steele JS, Janus ED, Sántamaria JD, Best JD (1992) Plasma apolipoprotein(a) is increased in type 2 (non-insulin-dependent) diabetic patients with microalbuminuria. Diabetologia 35: 1055-1059

33. Takegoshi T, Haba T, Hirai J et al. (1990) Alterations of lipoprotein(a) in patients with diabetic nephropathy. Atherosclerosis 83: 99-100

34. Wanner C, Rader D, Bartens Wet al. (1993) Elevated plasma lipoprotein(a) in patients with the nephrotic syndrome. Ann Intern Med 119: 263-269

35. Nielsen FS, Voldsgard AI, Gall M-A et al. (1993) Apolipoprotein(a) and cardiovascular disease in type 2 (non-insulin-dependent) diabetic patients with and without diabetic nephropathy. Diabetologia 36: 438-444

36. Dubrey SW, Reaveley DA, Leslie DG et al. (1993) Effect of insulin-dependent diabetes mellitus on lipids and lipoproteins: a study of identical twins. Clin Sci 84: 537-542

37. Heesen BJ, Wolffenbuttel BHR, Leurs PB et al. (1993) Lipoprotein(a) levels in relation to diabetic complications in patients with non-insulin-dependent diabetes. Eur J Clin Invest 23: 580-584
38. Maioli M, Tonolo G, Pacifico A et al. (1993) Raised serum apolipoprotein(a) in active diabetic retinopathy. Diabetologia 36: 88-90

39. Bruckert E, Davidoff P, Grimaldi A et al. (1990) Increased serum levels of lipoprotein(a) in diabetes mellitus and their reduction with glycemic control. JAMA 263: 35-36

40. Boomsma DI, Kaptein A, Kempen HJM, Leuven JAG, Princen HMG (1993) Lipoprotein(a): relation to other risk factors and genetic heritability. Results from a Dutch parent-twin study. Atherosclerosis 99: 23-33

41. Utermann G, Menzel HJ, Kraft HG, Duba HC, Kemmler HG, Seitz C (1987) Lp(a) glycoprotein phenotypes. Inheritance and relation to $\mathrm{Lp}(\mathrm{a})$ lipoprotein concentrations in plasma. J Clin Invest 80: 458-465

42. Jenner JL, Ordovas JM, Lamon-Fava S et al. (1993) Effect of age, sex, and menopausal status on plasma lipoprotein(a) levels. The Framingham offspring study. Circulation 87: 1135-1141

43. Cohn JS, Lam CWK, Sullivan DR, Hensley WJ (1991) Plasma lipoprotein distribution of apolipoprotein(a) in the fed and fasted states. Atherosclerosis 90: 59-66

44. Okura Y, Saku K, Hirata K et al. (1993) Serum lipoprotein(a) levels in maintenance hemodialysis patients. Nephron 65: 46-50

45. Rader DJ, Cain W, Zech LA, Usher D, Brewer HB Jr (1993) Variation in lipoprotein(a) concentrations among individuals with the same apolipoprotein(a) isoform is determined by the rate of lipoprotein(a) production. J Clin Invest 91: 443-447

46. Csaszar A, Dieplinger H, Sandholzer C et al. (1993) Plasma lipoprotein(a) concentration and phenotypes in diabetes mellitus. Diabetologia 36: 47-51 